\title{
Status epilepticus caused by an unusual encephalopathy
}

\author{
Michael Flower, Khalid Ali, Charlotte Lawthom
}

Department of Neurology, University Hospital of Wales, Cardiff, UK

\section{Correspondence to} Dr Michael Flower, University Hospital of Wales, Heath Park, Cardiff CF14 4XW, UK: michael.flower@cantab.net

Accepted 14 August 2014 Published Online First 10 September 2014

\section{CASE PRESENTATION}

An 18-year-old woman was admitted with recurrent seizures. These began focally in the left leg and rapidly generalised. She had complained of a mild generalised headache for the preceding 4 weeks, associated with rainbowcoloured lights in her central vision. On admission, she reported formed visual hallucinations, which included animals and vehicles. She had been previously well, she drank little alcohol, did not smoke, took only an oral contraceptive pill and had no significant family history.

On examination, she was apyrexial. There was continuous myoclonic jerking of the left arm and neck, left homonymous hemianopia, left hemiataxia and left hemisensory loss.

The myoclonus continued despite aggressive antiepileptic treatment with sodium valproate, levetiracetam and clobazam. She was intubated in a thiopentone-induced coma for $24 \mathrm{~h}$.

Investigations included normal routine haematology, biochemistry, haematinics and serum lactate dehydrogenase; tests for diabetes mellitus, pregnancy, syphilis and HIV were negative. CT scan of the head showed a right occipital hypodense area, reported as a possible infarct (figure 1A). A CT cerebral venogram was normal. MR scan of the brain showed right occipital and parietal cortical foci of T2 hyperintensity with gyral swelling (figure $1 \mathrm{~B}, \mathrm{C}$ ). There was no contrast enhancement or restricted diffusion. Cerebrospinal fluid $(\mathrm{CSF})$ protein was $1.04 \mathrm{~g} / \mathrm{L}$ (normal $\leq 0.4$ ) and CSF lactate was $2.5 \mathrm{mmol} / \mathrm{L}$ (normal $\leq 3)$. The opening pressure, cell count, cytology, glucose, oligoclonal bands, lactate dehydrogenase, viral PCR and cultures were normal or negative. Electroencephalogram (EEG) showed continuous right posterior spike-and-wave activity. MR angiography showed no vertebral artery dissection. Transthoracic echocardiogram was normal. Peripheral neurophysiology showed an axonal sensorimotor neuropathy and myopathic changes.

Two weeks later the myoclonus had continued. Repeat MR scan of the brain showed that the parietal hyperintensity had moved medially towards the longitudinal fissure and the occipital signal was more anterior in the lingual gyrus (figure 1D-F).

We considered an autoimmune encephalitis or malignant infiltration. Her migraine-like headache, progressive myoclonic epilepsy, stroke-like features and predominantly right-sided posterior disease prompted suspicion of mitochondrial disease.

Genetic testing for the mitochondrial DNA (mtDNA) mutations of mitochondrial encephalomyopathy with lactic acidosis and stroke-like episodes (MELAS) and myoclonic epilepsy with ragged red fibres (MERF) were negative. Nuclear gene testing found that she was homozygous for the c.1399G $>$ A base substitution (p.A467T amino acid substitution) in the polymerase- $\gamma$ gene (POLG). Both parents were later found to be carriers.

We stopped sodium valproate after a total of 60 days because of the risk of liver failure in POLG disease. Her seizures became well controlled with levetiracetam, eslicarbazepine acetate, perampanel and clobazam. We started ubiquinone and she left hospital after 66 days.

Unfortunately, 30 days later she became confused and jaundiced and the myoclonic jerking restarted. She was apyrexial with a Glasgow coma scale score of 12 out of 15. Inflammatory markers were normal, but liver function had acutely deteriorated, with serum bilirubin $320 \mu \mathrm{mol} / \mathrm{L}(1-22)$, alkaline phosphatase $210 \mathrm{U} / \mathrm{L}$ (45-105), alanine aminotransferase $90 \mathrm{U} / \mathrm{L}(5-35)$, albumin $19 \mathrm{~g} / \mathrm{L}$ (3749), prothrombin time $21 \mathrm{~s}$ (11.5-15.5) and activated partial thromboplastin time $49 \mathrm{~s}$ (30-40). She was conservatively managed by hepatologists and, because of impaired hepatic metabolism, we stopped 


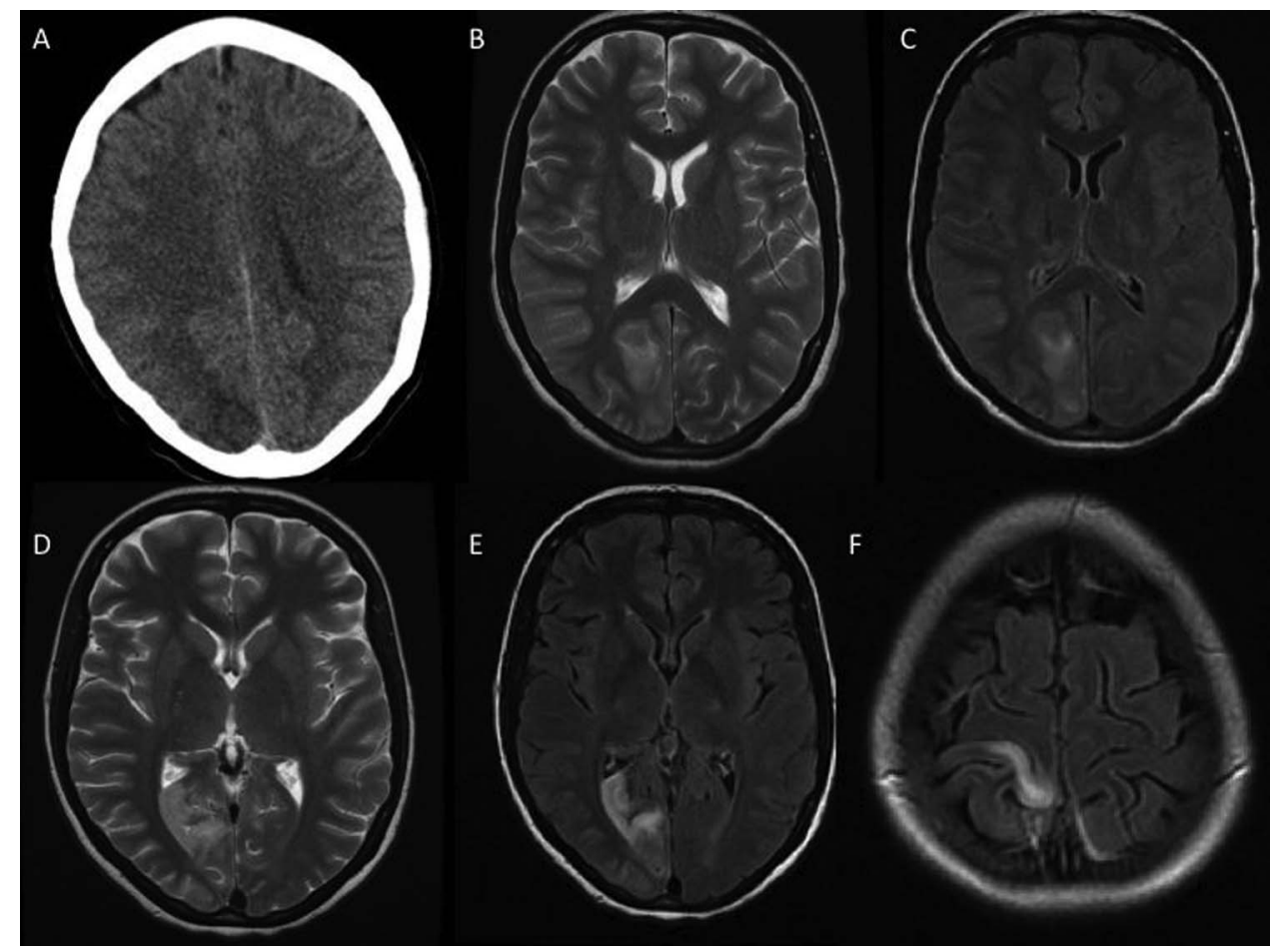

Figure 1 (A) Axial CT scan of head at presentation, showing a right occipital hypodense lesion. (B) Axial T2-weighted MR scan of brain at presentation, showing a right occipital hyperintense lesion with mass effect. There was also a similar right parietal lesion (not shown). (C) Axial FLAIR MR scan at the same level. (D) Axial T2-weighted and (E and F) FLAIR MR scan 2 weeks later, showing anterior movement of the occipital and medial movement of the parietal lesions.

eslicarbazepine acetate, perampanel and clobazam, and started topiramate and pregabalin. Over 3 weeks, her liver function improved, she became lucid, the myoclonic jerking resolved and she was once again discharged home. She remains seizure free, liver function is normal and she walks with an aid.

\section{DISCUSSION}

Mitochondria are cytoplasmic organelles present in all human cells, with a fundamental role in energy metabolism. They have their own DNA (mtDNA), ${ }^{1}$ which is maternally inherited. Recent work has shown that the vast majority of the estimated 1500

Table 1 Clinical phenotypes of POLG mutations

\begin{tabular}{|c|c|c|c|c|}
\hline Inheritance & Name & Other names & Clinical features & $\begin{array}{l}\text { Typical age at } \\
\text { onset (years) }\end{array}$ \\
\hline \multirow[t]{5}{*}{$\begin{array}{l}\text { Autosomal } \\
\text { recessive }\end{array}$} & Alpers-Huttenlocher syndrome & & $\begin{array}{l}\text { Liver dysfunction } \\
\text { Occipital epilepsy } \\
\text { Encephalopathy }\end{array}$ & $0-10$ \\
\hline & $\begin{array}{l}\text { Syndrome of sensory ataxic neuropathy } \\
\text { with ophthalmoparesis (SANDO) }\end{array}$ & $\begin{array}{l}\text { Autosomal recessive progressive external } \\
\text { ophthalmoplegia (arPEO) }\end{array}$ & $\begin{array}{l}\text { Progressive external } \\
\text { ophthalmoplegia } \\
\text { Axonal sensorimotor } \\
\text { neuropathy } \\
\text { Myopathy }\end{array}$ & $40-70$ \\
\hline & $\begin{array}{l}\text { Mitochondrial recessive ataxia syndrome } \\
\text { (MIRAS) }\end{array}$ & $\begin{array}{l}\text { Myoclonus, epilepsy, myopathy and } \\
\text { sensory ataxia (MEMSA) }\end{array}$ & $\begin{array}{l}\text { Occipital epilepsy } \\
\text { Myoclonus } \\
\text { Ataxia }\end{array}$ & $0-30$ \\
\hline & & $\begin{array}{l}\text { Ataxia neuropathy spectrum syndrome } \\
\text { (ANS) }\end{array}$ & $\begin{array}{l}\text { Ataxia } \\
\text { Axonal sensorimotor } \\
\text { neuropathy }\end{array}$ & \\
\hline & & Myocerebrohepatopathy syndrome (MCHS) & $\begin{array}{l}\text { Encephalopathy } \\
\text { Myopathy } \\
\text { Liver dysfunction }\end{array}$ & \\
\hline $\begin{array}{l}\text { Autosomal } \\
\text { dominant }\end{array}$ & $\begin{array}{l}\text { Autosomal dominant progressive external } \\
\text { ophthalmoplegia (adPEO) }\end{array}$ & & $\begin{array}{l}\text { Progressive external } \\
\text { ophthalmoplegia } \\
\text { Parkinsonism } \\
\text { Premature ovarian failure }\end{array}$ & $40-70$ \\
\hline
\end{tabular}




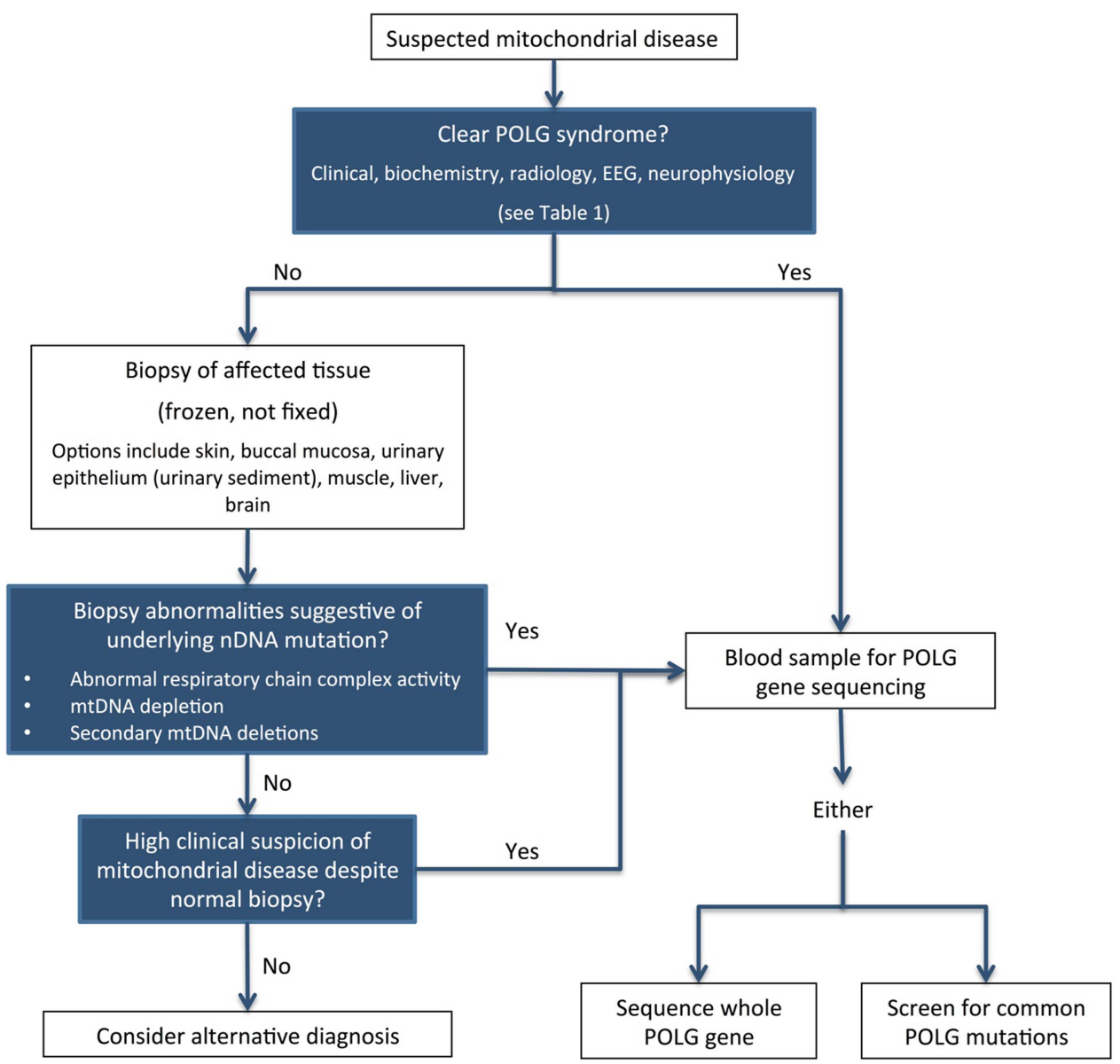

Figure 2 Suggested algorithm investigating mitochondrial disease associated with POLG mutations. EEG, electroencephalography; mtDNA, mitochondrial DNA.

mitochondrial proteins are encoded by nuclear DNA. This includes those governing replication and maintenance of the mitochondrial genome, such as polymerase- $\gamma$, from the POLG gene on chromosome $15 \mathrm{q} 25$, which replicates mtDNA. ${ }^{2}$

POLG mutations are the most common cause of mitochondrial disease currently known, accounting for up to $25 \%$ of cases. The carrier frequency of the most common mutation, A467T, is as high as 1\% in some European populations. ${ }^{2}$ The first pathogenic mutation was found in $2001,{ }^{3}$ but since then over 150 have been described. ${ }^{4}$

POLG mutations show a continuous spectrum of clinical features, including epilepsy, myoclonus, ataxia, encephalopathy, ophthalmoplegia, neuropathy and liver dysfunction. However, there are several distinct phenotypes (table 1). ${ }^{4}$

Figure 2 shows a suggested algorithm for genetic testing of POLG mutations. There are no consistent biochemical abnormalities. Serum and CSF lactate and CSF protein may be raised..$^{5}$ MR scan of the brain may show T2 and FLAIR hyperintense lesions in the occipital lobes (most often on the right), deep cerebellar nuclei, thalamus and basal ganglia, but can be normal, and changes can resolve. ${ }^{6}$ During active seizures, the EEG often shows an occipital focus. The occipital predilection is not fully understood; the occipital cortex is metabolically active, dealing with high-input visual stimulation, but whether this explains the phenomenon is unproven. Most have an axonal sensorimotor neuronopathy. ${ }^{7}$

Genetic counselling is complex. Though POLG mutations are autosomally inherited, there may be more than one mutation present, genetic factors modify the phenotype, clinical penetrance is unknown for many mutations and carriers may develop late onset mild disease. ${ }^{78}$ This case was autosomal recessive and both parents were heterozygous carriers of the A467T mutation. Pregnancy planning can be helped by prenatal diagnosis, either through amniocentesis at 15-16 weeks gestation or chorionic villus sampling at 11 weeks or by preimplantation genetic diagnosis through in vitro fertilisation.

No treatment cures or halts the progression of POLG disease. Most care is supportive and symptomatic. Patients significantly and irreversibly deteriorate after repeated seizures. No single or combination of antiepileptics is superior, but patients often require 
Table 2 Hepatic metabolism of common antiepileptic medications and recommendations in hepatic impairment ${ }^{10}$

\begin{tabular}{|c|c|c|}
\hline $\begin{array}{l}\text { Antiepileptic } \\
\text { medication }\end{array}$ & $\begin{array}{l}\text { Hepatic } \\
\text { metabolism }\end{array}$ & $\begin{array}{l}\text { Recommendations in } \\
\text { hepatic impairment }\end{array}$ \\
\hline $\begin{array}{l}\text { Benzodiazepines } \\
\text { (clobazam, } \\
\text { clonazepam) }\end{array}$ & Yes & $\begin{array}{l}\text { If treatment is necessary, } \\
\text { benzodiazepines with shorter } \\
\text { half-lives are safer. Avoid in } \\
\text { severe impairment }\end{array}$ \\
\hline Carbamazepine & Yes & Metabolism impaired \\
\hline $\begin{array}{l}\text { Eslicarbazepine } \\
\text { acetate }\end{array}$ & & Avoid in severe impairment \\
\hline Gabapentin & No & \\
\hline Lacosamide & No & Caution in severe impairment \\
\hline Lamotrigine & Yes & $\begin{array}{l}\text { Half dose in moderate } \\
\text { impairment, quarter in severe } \\
\text { impairment }\end{array}$ \\
\hline Levetiracetam & Minor & Half dose in severe impairment \\
\hline Oxcarbazepine & No & Caution in severe impairment \\
\hline Phenobarbital & Yes & Avoid in severe liver failure \\
\hline Phenytoin & Yes & Reduce dose to avoid toxicity \\
\hline Pregabalin & No & \\
\hline Rufinamide & Yes & $\begin{array}{l}\text { Caution in mild-moderate } \\
\text { impairment, avoid in severe } \\
\text { impairment }\end{array}$ \\
\hline Sodium valproate & Yes & Avoid \\
\hline Topiramate & Yes & Use with caution \\
\hline Vigabatrin & No & \\
\hline Zonisamide & Yes & Avoid in severe impairment \\
\hline
\end{tabular}

multiple medications at high doses. Sodium valproate should be avoided at all costs as it can cause fatal liver failure in autosomal recessive disease.

Breakthrough seizures should be treated aggressively. First-line treatments are benzodiazepines such as diazepam or lorazepam, followed by intravenous phenytoin or phenobarbital. If refractory, anaesthesia with propofol or thiopental should be used. ${ }^{6}{ }^{9}$ Antiepileptic treatment is particularly challenging in liver dysfunction and specialist advice should be sought (table 2). ${ }^{10}$

The prognosis of POLG is poor, with most patients dying after prolonged status epilepticus or liver failure. In A467T homozygotes-the most common mutation-epilepsy is the major prognostic factor. In a 10-year study, women were more likely to have epilepsy ( $75 \%$ vs $50 \%$ in men) and $59 \%$ of people with epilepsy died during the follow-up period. ${ }^{8}$ A paediatric study found that patients died, on average, 8.5 months after their first seizure. ${ }^{5}$ People without seizures had a milder course and remained ambulatory over decades. ${ }^{8}$

Mitochondrial disorders, though rare, will be considered in the differential of a wide range of neurological presentations and in patients with multisystem disorders. POLG mutation is now known to be the most common mitochondrial disease. While there is as yet no cure, greater awareness will improve diagnosis, and neurologists' involvement in front-line clinical management might influence disease course and prognosis. Aggressive seizure control and the avoidance of sodium valproate are paramount.

Contributors MF and KA wrote the article. MF did the literature search. CL supervised the process. CL still looks after the patient.

Competing interests CL has received speaker fees and advisory boards from Eisai, UCB and GSK.

Patient consent Obtained.

Provenance and peer review Not commissioned; externally peer reviewed. This paper was reviewed by Patrick Chinnery, Newcastle-upon-Tyne, UK.

\section{REFERENCES}

1 Nass S, Nass MMK. Intramitochondrial fibres with DNA characteristics. J Cell Biol 1963;19:593-629.

2 Saneto RP, Naviaux RK. Polymerase gamma disease through the ages. Dev Dis Res Rev 2010;16:163-74.

3 Van Goethem G, Dermaut B, Lofgren A, et al. Mutation of POLG is associated with progressive external ophthalmoplegia characterized by mtDNA deletions. Nat Genet 2001;28:211-12.

4 Chinnery PF, Zeviani M. 155th ENMC workshop: polymerase gamma and disorders of mitochondrial DNA synthesis. Neuromuscul Disord 2008;18:259-67.

5 Uusimaa J, Gowda V, McShane A, et al. Prospective study of POLG mutations presenting in children with intractable epilepsy: prevalence and clinical features. Epilepsia 2013;54:1002-11.

6 Tzoulis C, Engelsen BA, Telstad W, et al. The spectrum of clinical disease caused by the A467T and W748S POLG mutations: a study of 26 cases. Brain 2006;129:1685-92.

7 Lax NZ, Whittaker RG, Hepplewhite PD, et al. Sensory neuronopathy in patients harbouring recessive polymerase $\gamma$ mutations. Brain 2012;135(Pt 1):62-71.

8 Neeve VC, Samuels DC, Bindoff LA, et al. What is influencing the phenotype of the common homozygous polymerase- $\gamma$ mutation p.Ala467Thr? Brain 2012;135:3614-26.

9 Engelsen BA, Tzoulis C, Karlsen B, et al. POLG1 mutations cause a syndromic epilepsy with occipital lobe predeliction. Brain 2008;131:818-28.

10 British National Formulary [accessed Feb 2014]. 